\title{
Site correction of ground motion in Fujian area
}

\author{
Ying Zhang • Jinfu Zhang $\cdot$ Zhao Huang • \\ Chen Lin $\cdot$ Shanxiong Wang
}

Received: 30 July 2012/ Accepted: 27 October 2013/Published online: 26 December 2013

(C) The Seismological Society of China, Institute of Geophysics, China Earthquake Administration and Springer-Verlag Berlin Heidelberg 2013

\begin{abstract}
On the basis of the interpretation of the highresolution satellite remote sensing images, in combination with the data of engineering geological exploration and shear-wave velocity testing, the site category-zoning map of FJ area with the scale of 1:200,000 is generated according to the site classification standard of "Code for Seismic design of Buildings" of China (GB50011 2010). By the method of Probabilistic Seismic Hazard Analysis, we obtain bedrock seismic ground motion parameters of five recurrent periods $(50,200,500,1000$, and 2500 a) of FJ area. By using the 617 typical soil layer structures of the site classifications in FJ area, we build seismic response models of soil layers and make seismic response analysis, then obtain the statistic sample space of site amplification factors, which possess reasonable distribution and sufficient data. Considering the distribution characteristics of The Quaternary Strata in FJ area, according to the statistic zoning (mountains and coastal areas respectively) and site classifications as well as the level of bedrock importing ground motion, the site magnification-factors of ground motion in FJ area are obtained by classification statistics.
\end{abstract}

Keywords Ground motion - Site amplification factors · Coastal areas · Mountains - Site category - Fujian area

\section{Introduction}

As is known to all, for the same bedrock importing ground motion, if the engineering site classifications are different,

Y. Zhang · J. Zhang $(\bowtie) \cdot$ Z. Huang $\cdot$ C. Lin $\cdot$ S. Wang

Earthquake Administration of Fujian Province,

Fuzhou 350003, Fujian, China

e-mail: kcyf@163.com the ground destructions will have great deviation, which means that the earthquake destruction to swampy soil layers are much more serious than to rock.

Some studies indicated that the parameter values of ground motion on bedrock are very different from the values with soil layer amplification effect, the deviation between them can reach $250 \%$ (Allen et al. 2007). Therefore, the impact that specific site effect actions on ground motion parameter should be considered to offer rapidly and precisely the site seismic destructive influence, so as to preferably estimate some valuable information for the rapid seismic intensity reporting and seismic emergency relief.

Li et al. (2001) studied the effect of site conditions on the seismic ground motion with nonlinear analysis method, and put forward the adjustment method of design ground motion parameters for different site categories, thereinto the adjustment formulae for PGA and response spectra were:

$\mathrm{PGA}_{\mathrm{i}}=\mathrm{PGA} \cdot K_{\alpha \mathrm{i}}$

$S_{\mathrm{a}}(s)_{\mathrm{i}}=S_{\mathrm{a}} \cdot K_{\alpha \mathrm{i}}$

In the formula, $K_{\alpha \mathrm{i}}$ is the adjustment coefficient of different site classifications, namely the so-called "site amplification factors" in this paper.

In the ShakeMap system of USGS (Wald et al. 1999, 2006), the site amplification factors are given according to local site geology, which is represented with the average shear velocity from surface to $30 \mathrm{~m}$ underground $\left(V_{\mathrm{S}}^{30}\right)$. Some Chinese scholars utilized the principle of the similarity of surface geology and terrain (slope-gradient). After the slope-gradient calculation of the terrain DEM data of China mainland, then using the correlativity between slopegradient and $V_{\mathrm{S}}^{30}$ to get the approximate $V_{\mathrm{S}}^{30}$ in each site, 
and then using the $V_{\mathrm{S}}^{30}$ to quantize the ground motion site mu-factors (Chen et al. 2010), the research results are at great help to both rapidly, roughly estimating the ground motion distribution in seismic region and emergent decision after earthquake occurrence.

However, the precision of these methods is insufficient to provide ground motion correction for the online seismic intensity rapid report system.

Therefore, in this paper, on the basis of Fujian highresolution and multi-spectral satellite remote sensing image, combining the data of engineering geological exploration, shear-wave velocity (GB50011 2010) etc., as well as according to "Code for Seismic design of Buildings" of China (GB50011 2010), we determined the site classifications in the Fujian region and consequently generated the site classification zoning map in the Fujian region, the precision of which is 1:200,000.

The province-wide site amplification factors of different site classifications were computed statistically by Earthquake Safety Evaluation (ESE) calculation packet, and according to different site classifications, we computed statistically the site ground motion amplification factors respectively among in mountain, coastal areas, and different site classifications.

According to the site classification zoning and corresponding factors, the bedrock ground motions were corrected and obtained the site amplification factors table of different statistic regions in Fujian. This table can provide services for Fujian seismic intensity rapid report system.

Presented herein are the amplification factor of peak acceleration defines ratio between peak ground acceleration (PGA) and input peak bedrock acceleration, and the amplification factor of response spectrum defines ratio of each period spectral value between the surface and input bedrock response spectrums.

\section{Zoning of site classification}

The specific site conditions have great influence on the spreading of seismic wave and will affect the distribution of earthquake disasters directly. So, the zoning of site classification is important. In China, the engineering sites are divided into four categories. Fujian is a coastal province, mainly with mountainous region in its north. In this paper, we obtain the zoning of site category of Fujian, by means of the analysis of geomorphic discrimination and geological section.

First, on the basis of Fujian high-resolution and multispectral satellite remote sensing image interpretation, the province-wide nine cities (Ningde, Fuzhou, Putian, Quanzhou, Xiamen, Zhangzhou Nanping, Sanming and Longyan) adopted the $2.5 \mathrm{~m}$ high-resolution multi-spectral image to divide the Fujian geomorphology into nine types such as plain, platform, hill, mountain, basin, mountain valley, river valley, water area, isle, etc., and finally the geomorphology map of the FJ area were obtained.

Then, using the data of collecting or field engineering geological exploration obtained by field exploration, shearwave velocity test results in Fujian region, and according to "Code for Seismic design of Buildings" of China (GB50011 2010), we judge their site classifications for various boreholes.

Since the distribution of borehole points is uneven in whole province and in order to get the province-wide site classifications, Taylor polygon algorithm was adopted to finally determine the zoning result of site classification of the Fujian province.

According to incomplete statistics (Ding 1999), the distribution area of the Quaternary sedimentary strata in Fujian Province, is very small, only about $7,000 \mathrm{~km}^{2}$, accounting for less than $7 \%$ of the province's land area. It is mainly distributed in the coastal areas and river sides. The seismic damage on soft ground is quite harder than on hard one. Their effects to seismic ground motion are quite different.

In consideration of various factors such as Fujian actual terrain, landform, overburden cover, the coastal areas distribute thicker weak soil layer (like ooze, mucky soil etc.) and mountain areas distribute mainly mid-weak-midstrong soil (residual soil etc.), the geomorphic statistic zonation was divided into mountain (over $200 \mathrm{~m}$ altitude) and coastal (under $200 \mathrm{~m}$ altitude) so as to make a more precise Fujian site amplification factor table. The site category-zoning map of FJ area are shown in Fig. 1.

\section{The construction of bedrock ground motion distribution}

In terms of seismic engineering, according to the engineering characteristics, the seismic ground motion parameters can be divided into three types (Hu 1999): amplitude (peak parameters), shape of the response spectrum (spectrum) and strong motion duration. Different combinations of these three parameters determine the safety of structures under earthquake. In this paper, we mainly do research on the site amplification of seismic peak acceleration and response spectrum.

We obtain the province-wide distribution of bedrock ground motion by the method of Probabilistic Seismic Hazard Analysis (PSHA) which divided the whole province into grid of $0.1^{\circ} \times 0.1^{\circ}$ to get total 1,350 calculation points.

In order to simplify the input, the risk calculation points (69 in total), which closest to grid and covering the 


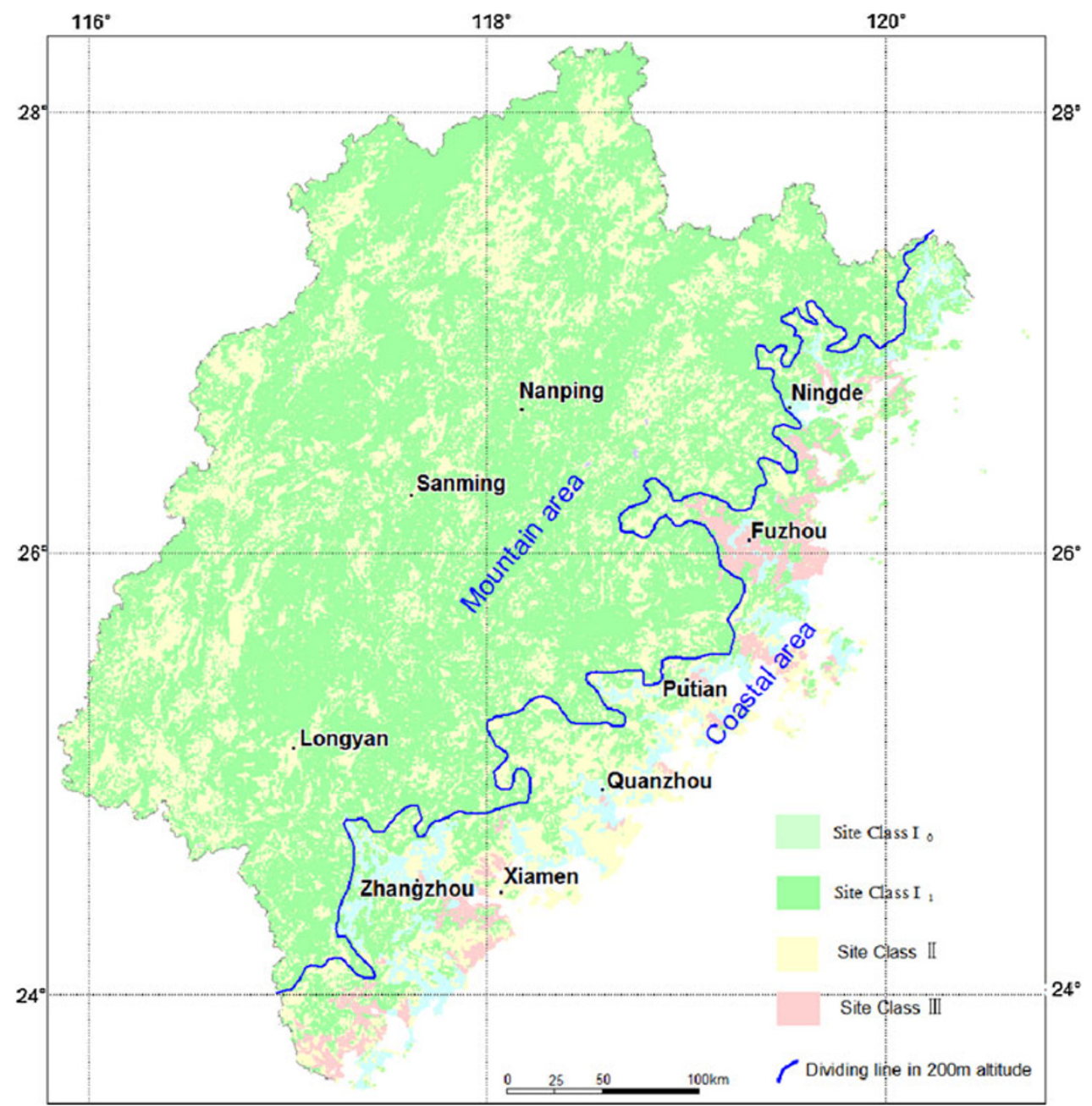

Fig. 1 The site category-zoning map of Fujian area

Table 1 Ground motion input peak acceleration table for each prefecture in Fujian (Gal)

\begin{tabular}{|c|c|c|c|c|c|c|c|}
\hline \multirow[t]{2}{*}{ Prefecture } & \multirow[t]{2}{*}{ Longitude $\left({ }^{\circ} \mathrm{E}\right)$} & \multirow[t]{2}{*}{ Latitude $\left({ }^{\circ} \mathrm{N}\right)$} & \multicolumn{5}{|c|}{ Recurrent period (a) } \\
\hline & & & 50 & 200 & 500 & 1,000 & 2,500 \\
\hline Fuzhou & 119.3 & 26.1 & 25.7 & 49.4 & 73.3 & 102.4 & 148.2 \\
\hline Longyan & 117.0 & 25.1 & 21.4 & 41.9 & 59.9 & 78.8 & 108.1 \\
\hline Ningde & 119.5 & 26.7 & 18.5 & 33.8 & 47.6 & 61.4 & 83.2 \\
\hline Nanping & 118.2 & 26.7 & 13.9 & 27.7 & 42.9 & 60.7 & 91.2 \\
\hline Putian & 119.0 & 25.4 & 29.0 & 56.1 & 85.5 & 119.7 & 172.8 \\
\hline Quanzhou & 118.6 & 24.9 & 35.2 & 79.0 & 127.8 & 180.4 & 260.0 \\
\hline Sanming & 117.6 & 26.3 & 15.8 & 31.4 & 46.8 & 62.2 & 86.9 \\
\hline Xiamen & 118.1 & 24.5 & 36.4 & 88.1 & 148.6 & 220.0 & 320.0 \\
\hline Zhangzhou & 117.7 & 24.5 & 32.7 & 77.1 & 130.0 & 197.1 & 310.0 \\
\hline
\end{tabular}

province-wide county-above cantons, were selected as input values of bedrock ground motion field.

In the Table 1, the input ground motion peak acceleration values of various cities in the Fujian province-wide were listed.
In this paper, we select the acceleration peak values of seismic wave which have 50 a recurrent period (10-45 Gal), 200 a recurrent period (21-112 Gal), 500 a recurrent period $(32-177 \mathrm{Gal}), 1,000$ a recurrent period (70-360 Gal), and 2,500 a recurrent period (70-360 Gal). 


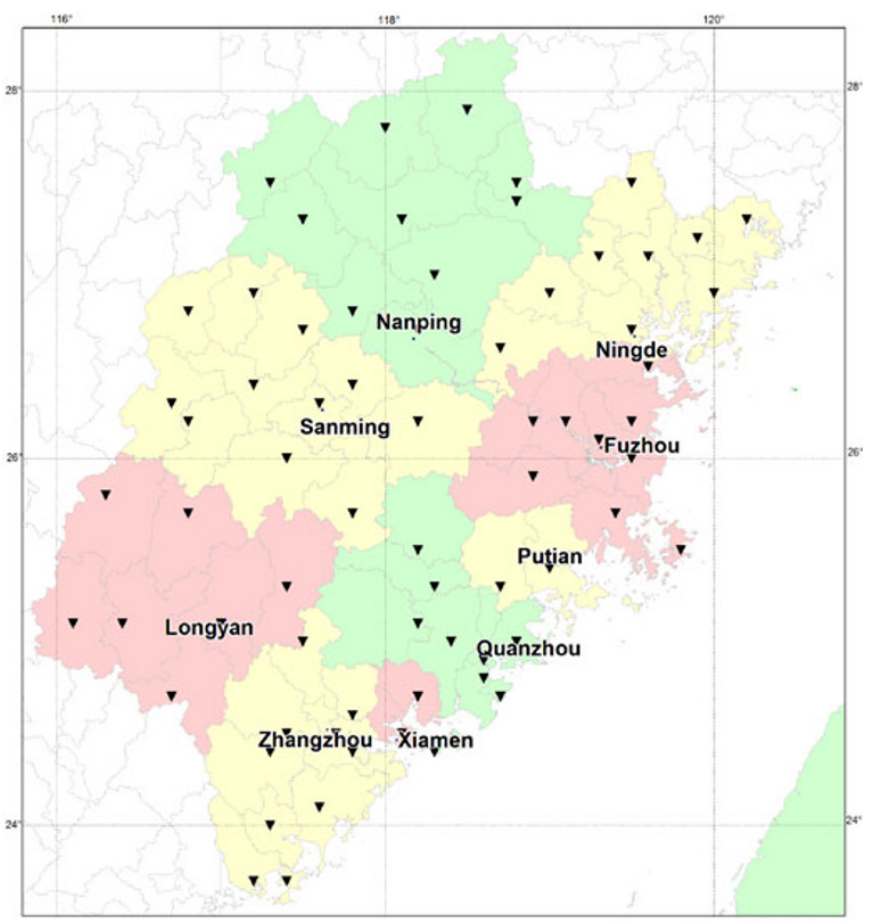

V Distribution of bedrock ground-motion input points ${ }^{0} \quad 50 \quad 100 \mathrm{~km}$
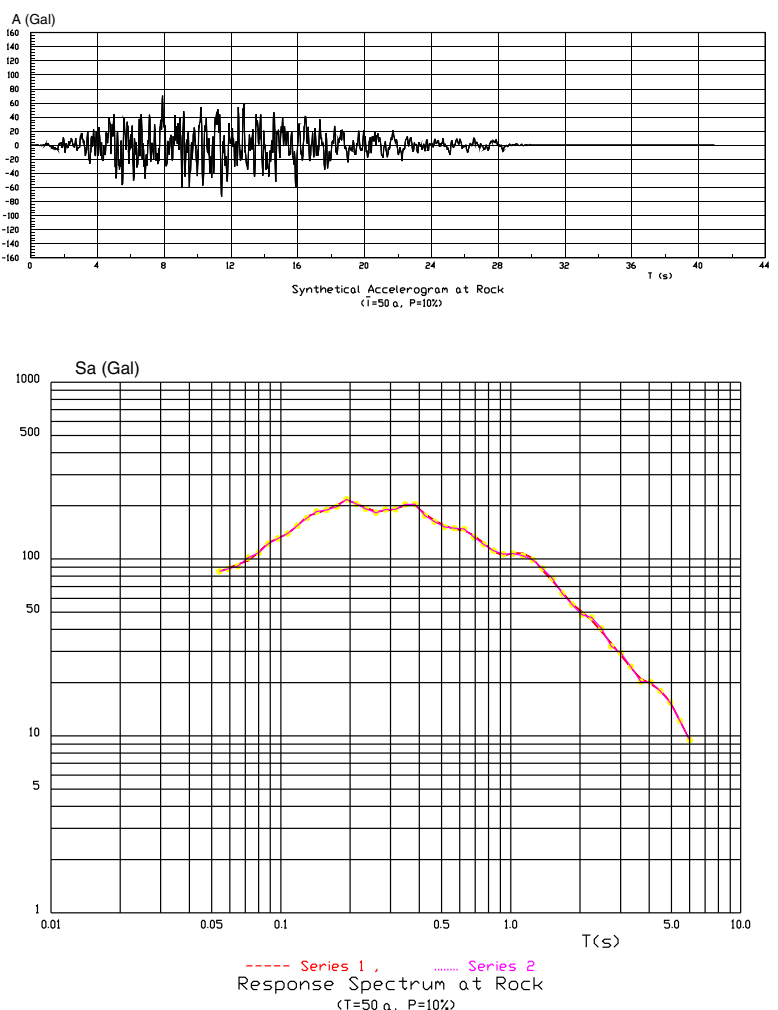

Fig. 2 Distribution of the Fujian bedrock ground motion input points and synthesized bedrock ground motion time-histories (recurrent period is 500 a)

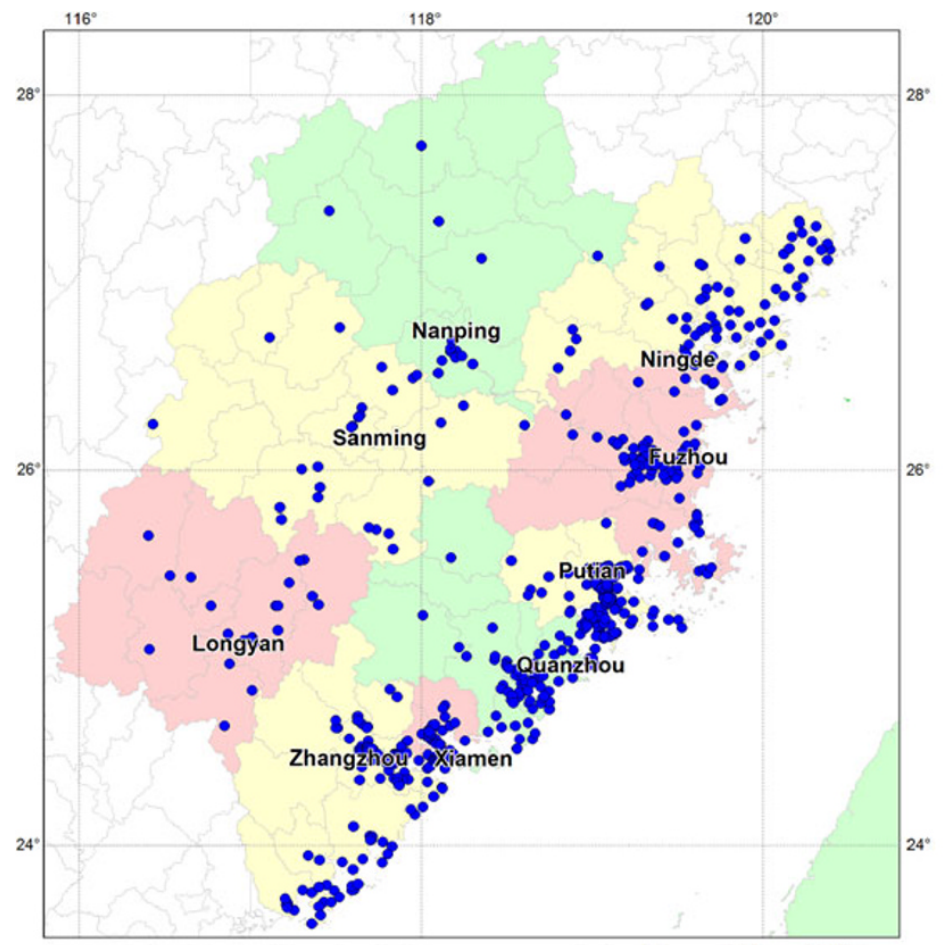

- Soil profile position of seismic response analysis

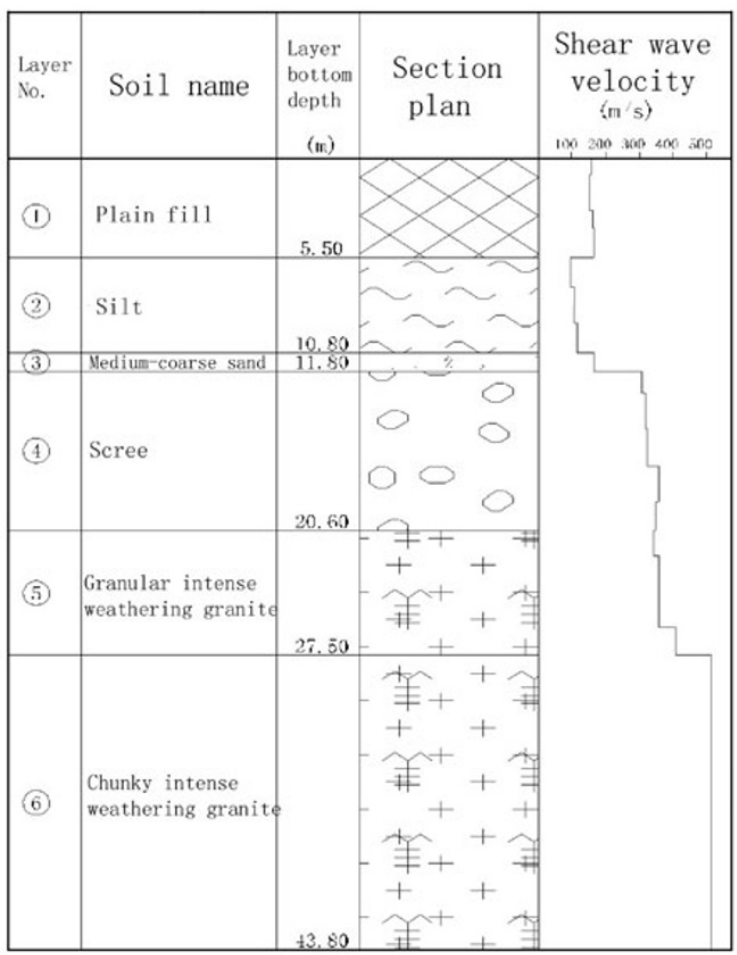

Fig. 3 Fujian soil layer response calculation boreholes and columnar model 


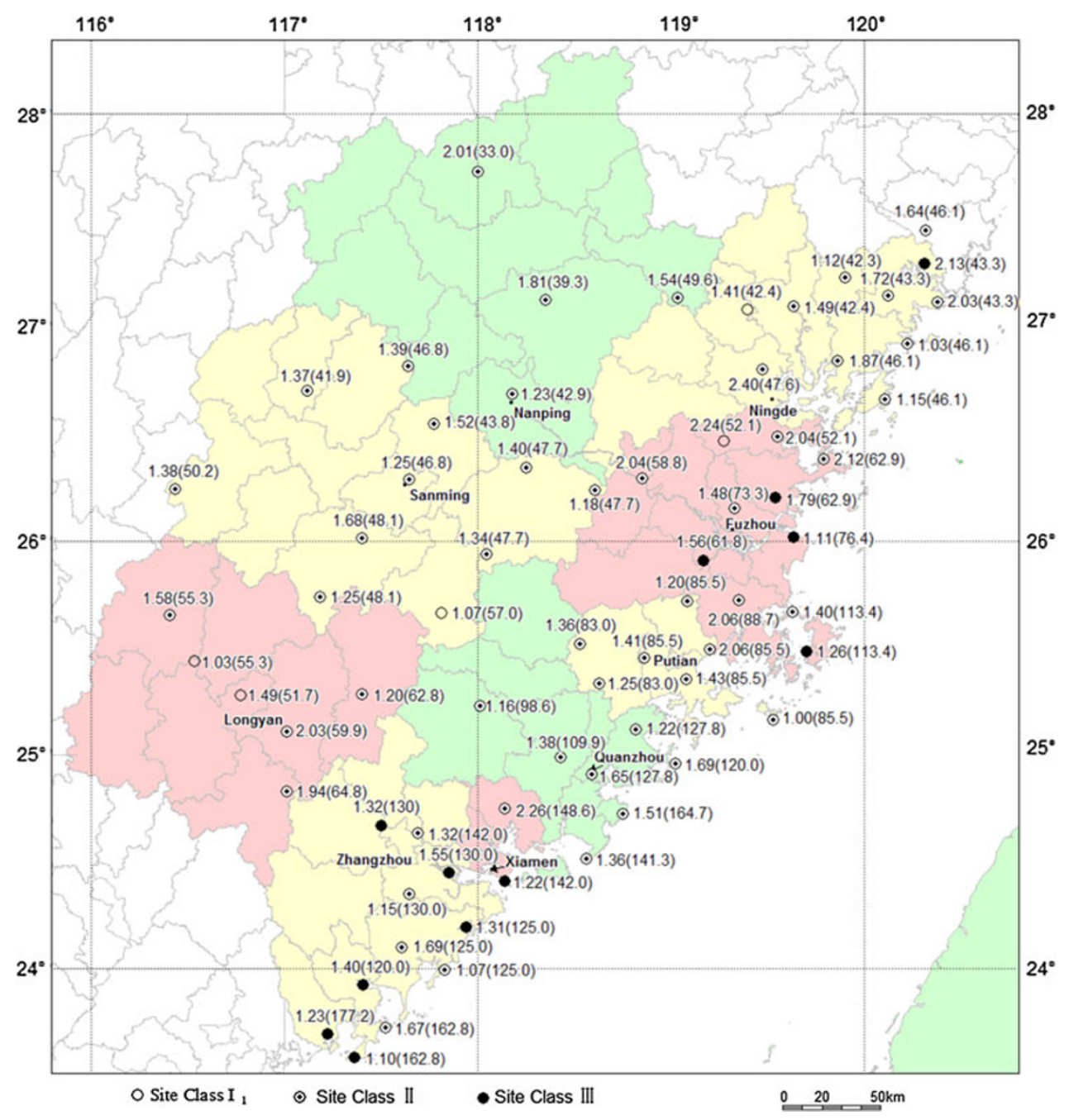

Fig. 4 Site amplification factors of peak acceleration in Fujian

Since moderate and small earthquakes occurred in the Fujian region are predominate, but the effect of moderate and strong earthquakes mainly come from Taiwan region, we must select appropriate bedrock ground motion input values $(10-360 \mathrm{Gal})$ so as to divide the different effects of moderate and small earthquakes. Accordingly, we obtain the statistical sample space of site amplification factors with reasonable even distribution and sufficient datum.

The distribution of the Fujian bedrock ground motion input points, typical ground motion time-histories, and response spectrum-fit graph are shown in Fig. 2.

We adopt the strongly and moderately weathered rock surface with a sheer-wave velocity over $500 \mathrm{~m} / \mathrm{s}$ as the seismic wave input surface. The trigonometric series method is used to synthesize the artificial bedrock ground motion time-histories as the bedrock seismic input waves for soil layer ground motion reflection analysis.

\section{The construction of soil layer response analysis model}

In the response spectrum calculation of the soil layer ground motion in the Fujian provincewide, first according to the collection of the field geotechnical drilling and soil layer geotechnical data, the data of total 617 borehole points were obtained. Among them, 21 points belong to site-class I (except free-bedrock sites in site-class I sites); 450 points belong to site-class II; 146 points belong to siteclass III. In the site calculating model, the sites of site-class II are maximum because they are most familiar in engineering sites and mainly be concerned.

The columnar section parameter models of soil layer ground motion response for each several boreholes were established, which depended on drilling geologic histogram, soil layer shear-wave velocity test result (Fig. 3), geotechnical test data result, and soil dynamic feature parameter test results. 


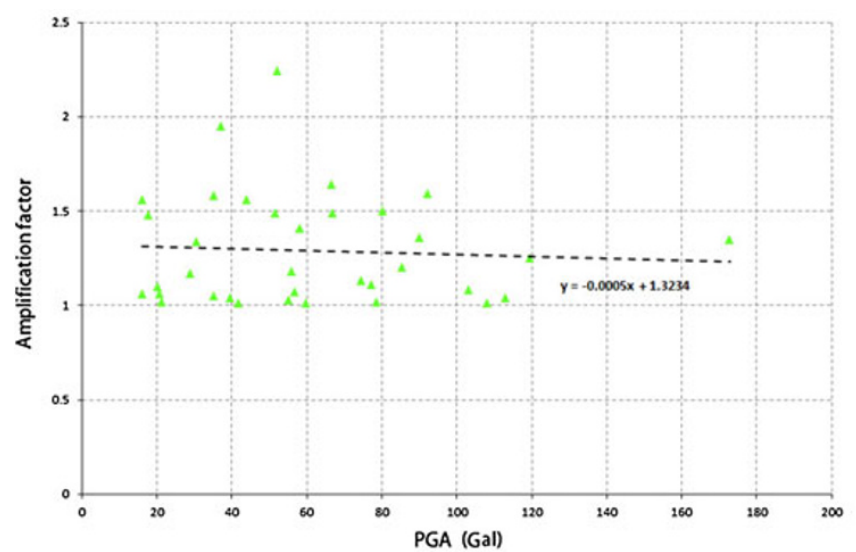

Coastal \& Mountain site class

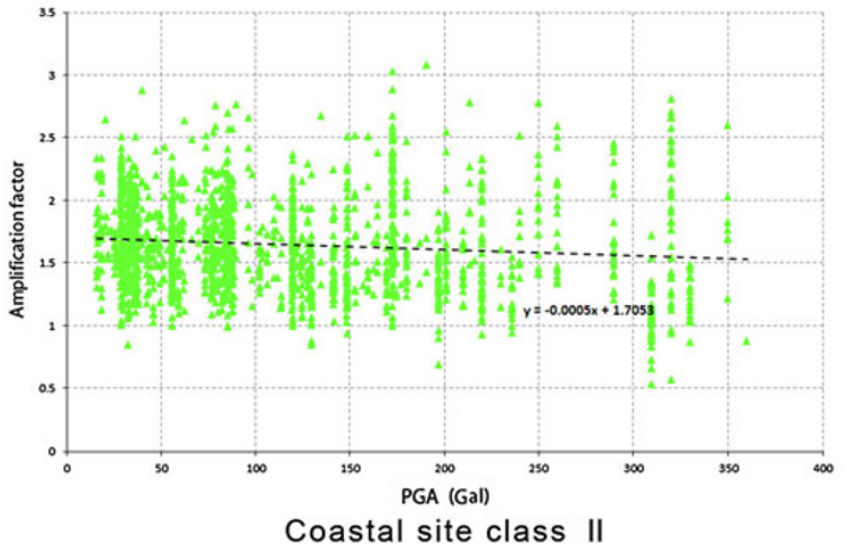

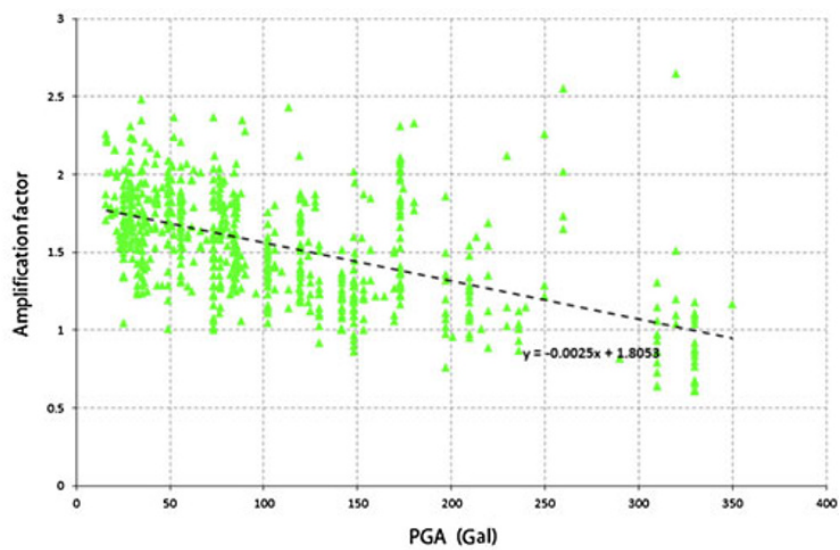

Coastal site class III

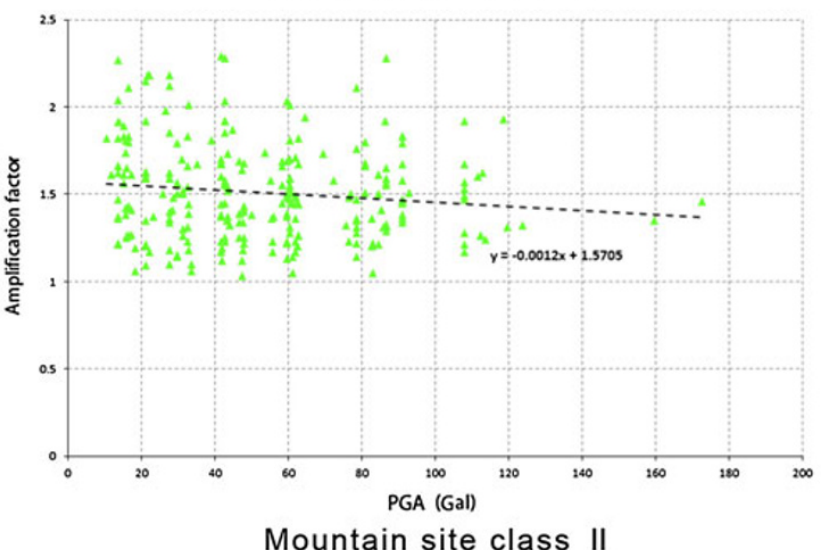

Fig. 5 Relationship between input bedrock peak acceleration and amplification factors (coastal sites class II and III)

Table 2 Fujian coastal sites peak acceleration amplification factors

\begin{tabular}{|c|c|c|c|c|c|c|}
\hline \multirow[t]{2}{*}{ Site classification } & \multicolumn{6}{|c|}{ Bedrock ground motion intensity (peak acceleration) $A_{\max }(g)$} \\
\hline & $0-50$ & $50-100$ & $100-150$ & $150-200$ & $200-300$ & $>300$ \\
\hline $\mathrm{I}_{0}$ & 1.00 & 1.00 & 1.00 & 1.00 & 1.00 & 1.00 \\
\hline$I_{1}$ & 1.14 & 1.13 & 1.09 & 1.07 & 1.06 & 1.05 \\
\hline II & 1.69 & 1.68 & 1.65 & 1.62 & 1.60 & 1.47 \\
\hline III & 1.74 & 1.64 & 1.59 & 1.52 & 1.40 & 1.35 \\
\hline
\end{tabular}

Table 3 Fujian mountainous sites peak acceleration amplification factors

\begin{tabular}{llllll}
\hline Site classification & \multicolumn{5}{l}{ Bedrock ground motion intensity (peak acceleration) $\mathrm{A}_{\max }(\mathrm{g})$} \\
\cline { 2 - 6 } & $0-50$ & $50-100$ & $100-150$ & $150-200$ & $200-300$ \\
\hline $\mathrm{I}_{0}$ & 1.00 & 1.00 & 1.00 & 1.00 & 1.00 \\
$\mathrm{I}_{1}$ & 1.14 & 1.13 & 1.09 & 1.07 & 1.06 \\
$\mathrm{II}$ & 1.54 & 1.48 & 1.46 & 1.45 & 1.00 \\
\hline
\end{tabular}



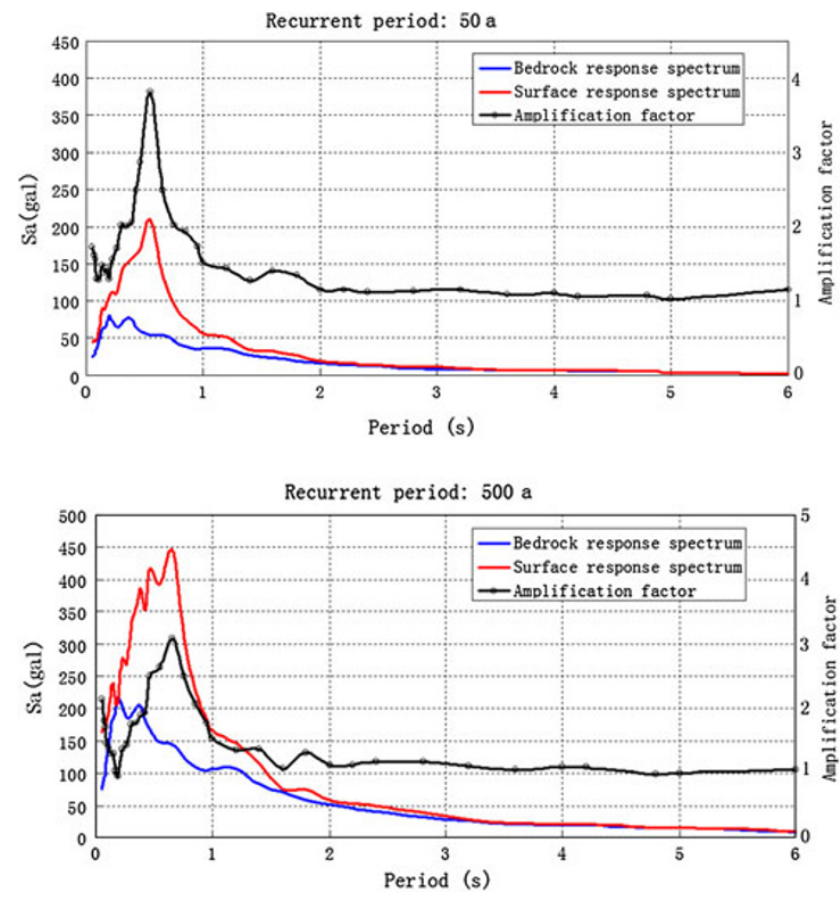

Fig. 6 Site response spectrum amplification factors (coastal II-type)

We compute soil layer ground motion response by one-dimensional equivalent linearization wave method whose procedure using ESE software proposed by China Earthquake Administration. The rock ground motion time-histories and response spectrum of five recurrent periods and 35 period points, which were obtained by PSHA, were both used to compute soil layer response for getting the peak acceleration value and response spectrum value of surface soil layer response of each several boreholes.

Typical soil dynamic non-linear characteristics equivalent curve parameter graph (Fig. 3).

\section{The statistics of site amplification factors}

Using the model of ground motion analysis which was builded by 617 borehole point data to calculate seismic response respectively for the calculating models of the input bedrock seismic time-histories in each sites so as to get the ground motion peak acceleration response spectrum of site-free surface in each sites.

Since the figure-size was limited, in Fig. 4, it merely was listed that the amplification factors of typical boreholes around 69 counties and cities.

Due to the site-class IV sites do not exist in the Fujian land areas; the site-class III sites only exist in Fujian coastal areas, so when conducting the site amplification

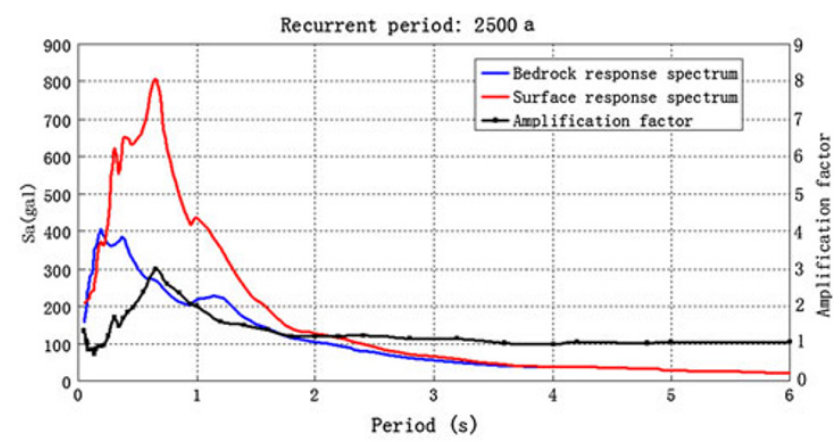

factor statistics, the site-class IV sites in inshore, site-class III and IV sites in mountains will be excluded.

\subsection{The statistics of peak ground motion acceleration amplification factors}

The site amplification factors of peak acceleration of ground motion are obtained by statistics according to the following conditions:

1. Geomorphic classifications: to differentiate mountainous areas (over $200 \mathrm{~m}$ altitude) from coastal areas (under $200 \mathrm{~m}$ ).

2. Site classifications:

Coastal statistic zones were divided into classes $\mathrm{I}_{0}, \mathrm{I}_{1}, \mathrm{II}$, and III, four statistic units in total.

Mountains statistic zones were divided into classes $\mathrm{I}_{0}, \mathrm{I}_{1}$, and II, three statistic units in total.

In this article, since there is merely 21 boreholes in sites class $I_{1}$ samples and without obvious cover thickness variation $(0-5 \mathrm{~m})$, the statistics of sites class $\mathrm{I}_{1}$ in coastal and mountainous areas will be combined.

Magnification statistical curve and figure for $\mathrm{I}_{0}, \mathrm{I}_{1}$, II and III coastal areas and $\mathrm{I}_{0}, \mathrm{I}_{1}$ and II mountains of Fujian are shown in Fig. 5.

Peak acceleration amplification factors of various site classifications from two statistic zones of Fujian coastal areas and mountains are tabulated in Tables 2 and 3. 
5.2 The statistics of site response spectrum amplification factors

The site amplification factors of response spectrum are obtained by statistics according to the same conditions as those of PGA in geomorphic classifications and site classifications. In addition, there are other conditions as below:

(1) Peak acceleration zones: the coastal areas were divided into 0-50, 50-100, 100-200, and above $200 \mathrm{Gal}$, whereas mountainous were divided into 0-50, 50-100, and above $100 \mathrm{Gal}$. On China ground motion parameters zoning map, mountains mainly distribute in the north and west in Fujian with the peak ground motion acceleration less or equal to $0.1 \mathrm{~g}$ zone. Therefore, the statistics for mountains over $200 \mathrm{Gal}$ will be excluded for the lack of sample data.

(2) Response spectrum period dividing: conducting statistics regression for the response spectrum values of shortperiod $F_{\mathrm{a}}(0.1-0.5 \mathrm{~s})$, medium-period $F_{\mathrm{v}}(0.5-2.0 \mathrm{~s})$, and long-period $F_{\mathrm{d}}(2.0-6.0 \mathrm{~s})$.

The statistics of the relationship between each response spectrum period-point and amplification factors was conducted on the various site classifications of the Fujian coastal and mountainous areas. In order to explicate the characteristics of response spectrum amplification factors, the amplification factors curve is stacked together with the response curve of bedrock and ground-surface (Fig. 6).

Figure 6 indicates that, for the same calculation boreholes, with the increase of bedrock peak accelerations, along the timeline, the maximum amplification factors trend to increase but the magnification time shows reverse trend: the maximum amplification factors of 3.82(0.55), $3.08(0.65)$, and $2.99(0.65)$, respectively, correspond to the return period level (period s) of 50, 500, and $2500 \mathrm{a}$. Moreover, the amplification factors curve tends to a linear straight up in the first half period and to an exponential decay in the latter half period. In consideration of those above and the own characteristic of the acceleration response spectrum, a proper function was selected to synthesize the sample data:

$y(x)= \begin{cases}A+B x & 0<x \leq 0.5 \mathrm{~s} \\ (A+0.5 B)\left(\frac{0.5}{x}\right)^{\gamma} & 0.5<x \leq 6.0 \mathrm{~s}\end{cases}$

In the formula, $A, B$, and $\gamma$ here are simulation parameters. Based on the sample data gained (i.e., the response spectrum ratio between the input bedrock and the ground-surface), the amplification factors simulation curve of ground-surface acceleration response spectrum about different period points and different site classifications was created (Fig. 7).

The determining principle for the acceleration response spectrum amplification factors of various period zones is: adopting the mean values for the response spectrum simulation curves that are corresponding to the period zones of short-period (0.1-0.5 s), medium-period (0.5-2 s), and long-period (2-6 s). Site response spectrum periods and amplification factors of coastal and mountainous areas are shown in Tables 4 and 5.

The two tables above indicate that, both being site-class II, there is a large difference between the impact factors statistic results of coastal areas and mountains, which is caused by the impact of the quaternary-period weak soil layer that commonly exist in coastal areas.

The two tables show that, the site amplification factors for long-period are normally larger than short-period in response spectrum, which is most obvious in site-class III and coastal site-class II. It represents the selectivity of the site impact magnification action in the different response spectrum periods, which is with thicker cover and weaker site soil, the impact to the long-period values of response spectrum will be more obvious.

\section{Comparison with the other research results}

\subsection{The research of site Amplification factors at home and abroad}

Most of the external research results are dividing site classes according to the site classification standard of American NEHRP, which divides sites into the six classes of $\mathrm{A}, \mathrm{B}, \mathrm{C}, \mathrm{D}, \mathrm{E}$, and $\mathrm{F}$ per the equivalent sheer-wave velocity $V_{30}$ of $30 \mathrm{~m}$ underground. According to the comparison of the China and US site classifications made by Lu and Zhao (2007), this article listed their approximate correspondence relation in Table 6 .

The impact factors of site-class IV (equivalent to E) will not be compared in the article, for there is no exist sites class IV in the Fujian land area.

The external studies on ground motion site impact mostly adopt the ground motion attenuation relationship between bedrock and soil layer to calculate the response spectrum of bedrock and site. The peak acceleration ratio of soil layer and bedrock was chosen to be PGA magnification coefficient, and the short-period magnification coefficient $F_{\text {a }}$ and the medium-period magnification coefficient $F_{\mathrm{v}}$ were obtained from the response spectrum ratio of different period.

Among them, Atkinson and Boore (2003) use the attenuation relationship of absolute acceleration response spectrum to statistically gain the PGA magnification coefficients, as shown in Table 7.

Some Chinese scholars have carried out research on the subject. Li et al. (2001) applied the method of non-linear ground motion response value analysis to study the 

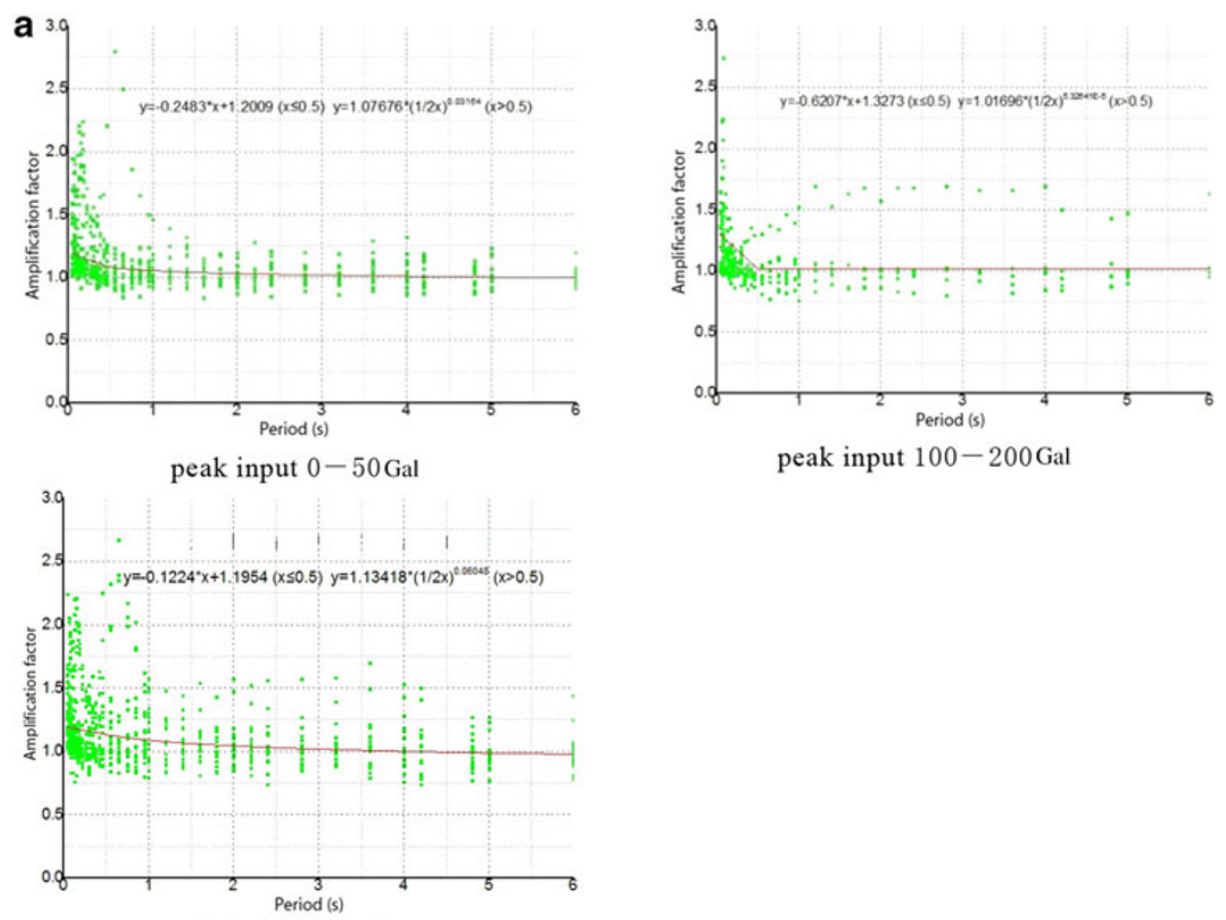

peak input $100-200 \mathrm{Gal}$

peak input $50-100 \mathrm{Gal}$
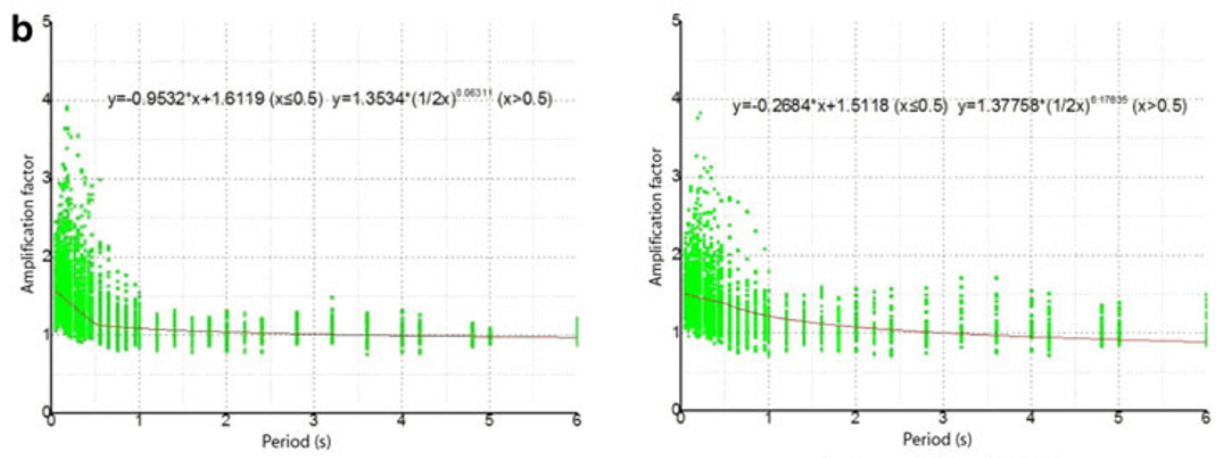

peak input $0-50 \mathrm{Gal}$

peak input $50-100 \mathrm{Gal}$

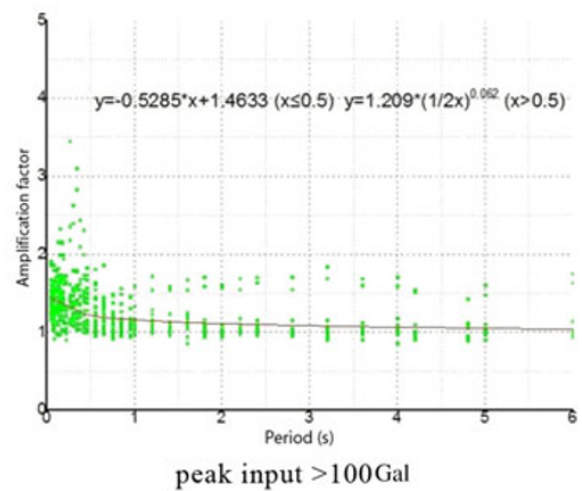

Fig. 7 a The relationship between site response spectrum period and amplification factors (coastal and mountainous areas, $I_{1}$-type). b The relationship between site response spectrum period and amplification factors. $\mathbf{c}$ The relationship between site response spectrum period and amplification factors. $\mathbf{d}$ The relationship between site response spectrum period and amplification factors

relationship between peak acceleration ratios of site ground-surface motion and bedrock ground motion under different site conditions, when China ground motion parameter zoning map GB18306-2001 (2001) was compiled. Then, a peak acceleration correction table for different site ground motion is shown in Table 8 . 

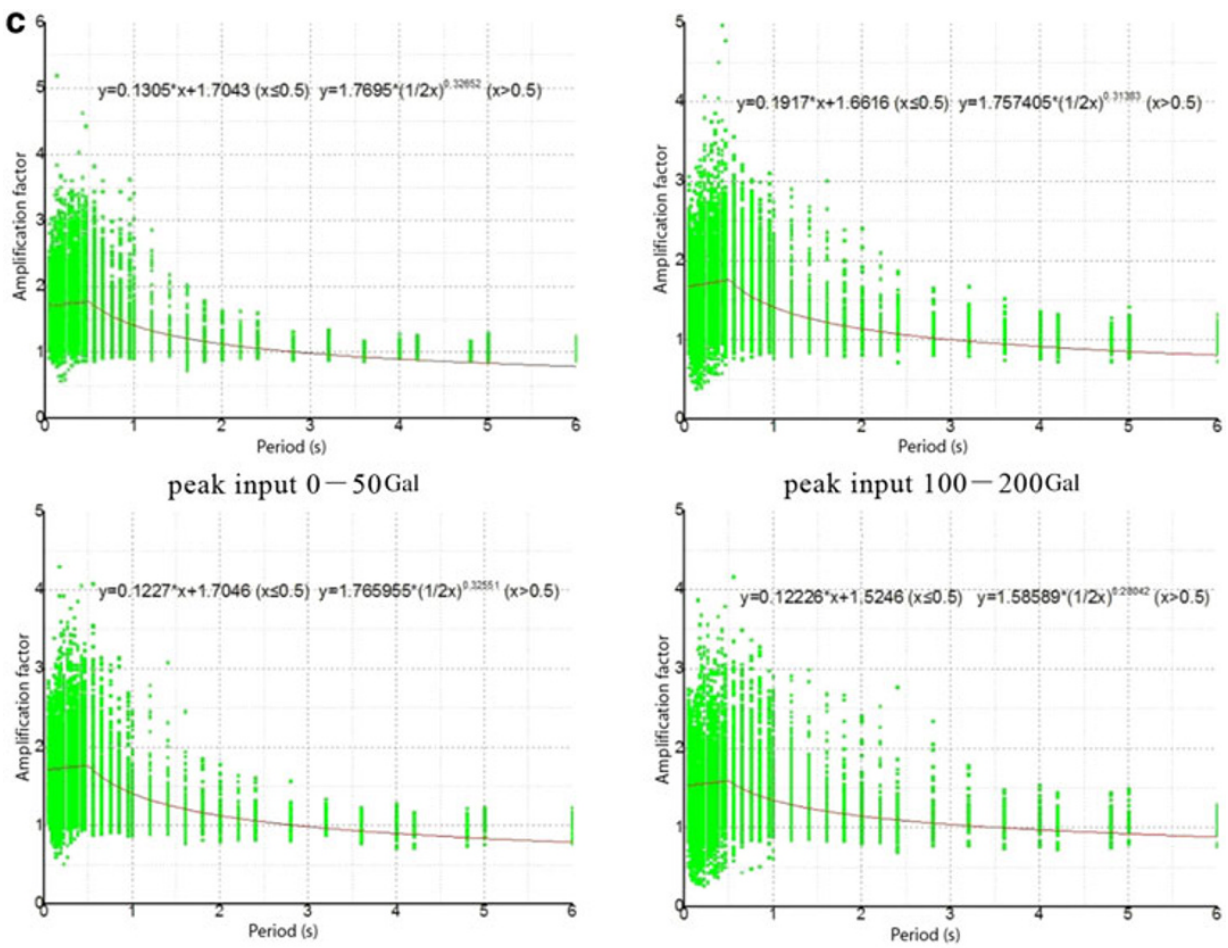

peak input $50-100 \mathrm{Gal}$

peak input $>200 \mathrm{Gal}$
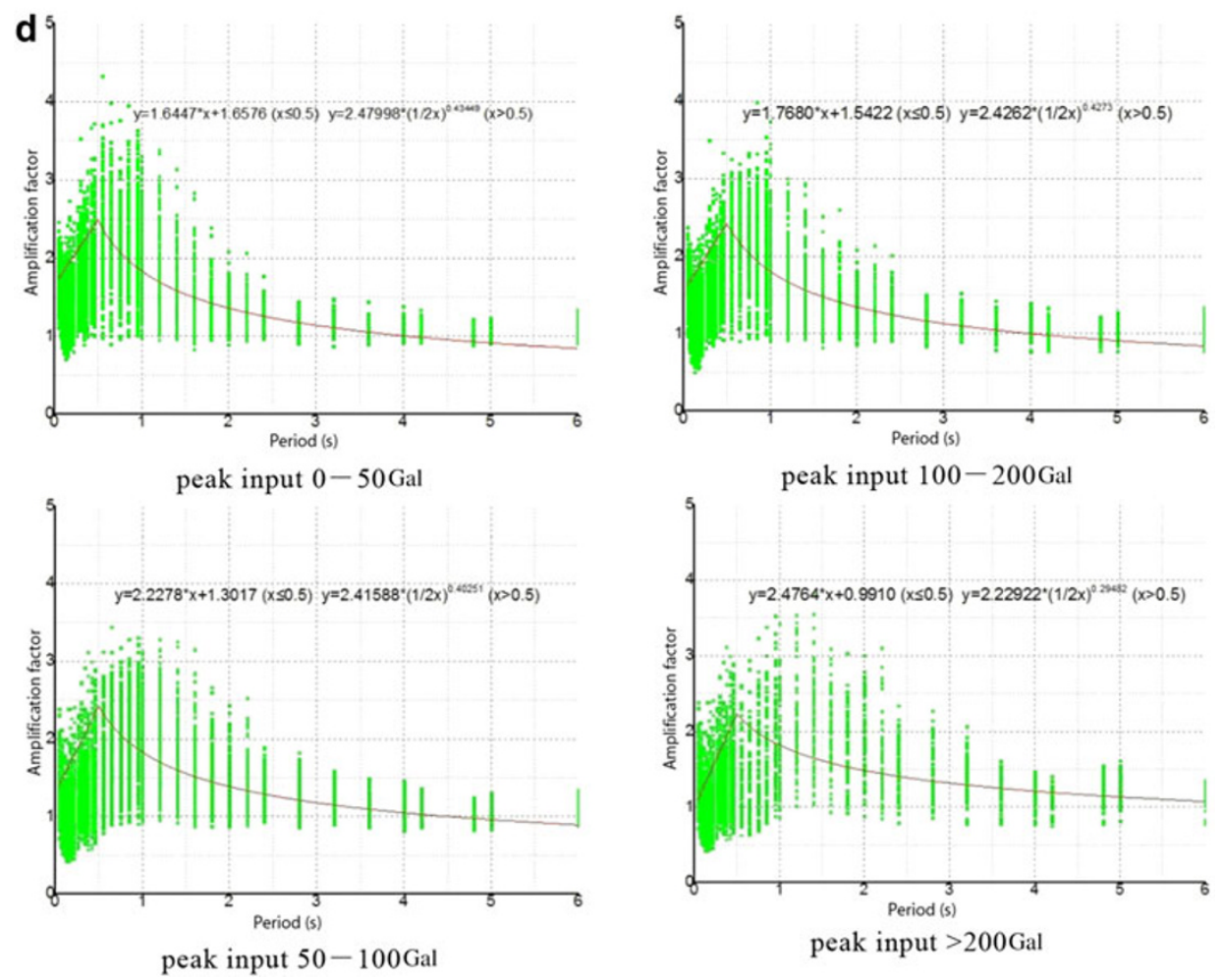

Fig. 7 continued

The amplification factors are shown in Tables 7 and 8 indicate that, the amplification factors tend to decrease along with the increase of peak acceleration, which shows quite a consistency in the table. The amplification factors range ability of C, D, and E sites are relatively small for short-period magnification coefficient $F_{\mathrm{a}}$. Whereas the amplification factors range ability of $\mathrm{C}, \mathrm{D}$, and $\mathrm{E}$ sites are relatively large for the medium-period magnification coefficient $F_{\mathrm{v}}$. 
Table 4 Coastal site ground motion response spectrum amplification factors

\begin{tabular}{|c|c|c|c|c|c|c|c|c|c|c|c|c|}
\hline \multirow[t]{2}{*}{ Site classification } & \multicolumn{4}{|c|}{ Short-period $(0.1-0.5 \mathrm{~s})$} & \multicolumn{4}{|c|}{ Medium-period $(0.5-2.0 \mathrm{~s})$} & \multicolumn{4}{|c|}{ Long-period $(2.0-6.0 \mathrm{~s})$} \\
\hline & $0-50$ & 50-100 & $100-200$ & $>200$ & $0-50$ & $50-100$ & 100-200 & $>200$ & $0-50$ & $50-100$ & $100-200$ & $>200$ \\
\hline $\mathrm{I}_{0}$ & 1.00 & 1.00 & 1.00 & 1.00 & 1.00 & 1.00 & 1.00 & 1.00 & 1.00 & 1.00 & 1.00 & 1.00 \\
\hline $\mathrm{I}_{1}$ & 1.26 & 1.26 & 1.19 & 1.15 & 1.18 & 1.18 & 1.07 & 1.05 & 1.09 & 1.08 & 1.07 & 1.06 \\
\hline II & 1.72 & 1.65 & 1.55 & 1.45 & 1.38 & 1.36 & 1.34 & 1.33 & 1.05 & 1.04 & 1.04 & 1.03 \\
\hline III & 1.59 & 1.39 & 1.17 & 1.10 & 1.90 & 1.85 & 1.84 & 1.79 & 1.35 & 1.18 & 1.14 & 1.13 \\
\hline
\end{tabular}

Table 5 Mountains site ground motion response spectrum amplification factors

\begin{tabular}{|c|c|c|c|c|c|c|c|c|c|}
\hline \multirow[t]{2}{*}{ Site classification } & \multicolumn{3}{|c|}{ Short-period $(0.1-0.5 \mathrm{~s})$} & \multicolumn{3}{|c|}{ Medium-period $(0.5-2.0 \mathrm{~s})$} & \multicolumn{3}{|c|}{ Long-period $(2.0-6.0 \mathrm{~s})$} \\
\hline & $0-50$ & $50-100$ & $>100$ & $0-50$ & $50-100$ & $>100$ & $0-50$ & $50-100$ & $>100$ \\
\hline $\mathrm{I}_{0}$ & 1.00 & 1.00 & 1.00 & 1.00 & 1.00 & 1.00 & 1.00 & 1.00 & 1.00 \\
\hline $\mathrm{I}_{1}$ & 1.26 & 1.26 & 1.19 & 1.18 & 1.18 & 1.07 & 1.09 & 1.08 & 1.07 \\
\hline II & 1.52 & 1.49 & 1.46 & 1.13 & 1.11 & 1.08 & 1.06 & 1.03 & 1.02 \\
\hline
\end{tabular}

Table 6 China and US site classification correspondence relation

\begin{tabular}{|c|c|c|c|c|c|c|c|c|}
\hline China & $\mathrm{I}_{0}$ & & $\mathrm{I}_{1}$ & II & & III & & IV \\
\hline NEHRP US & A & B & $\mathrm{BC}$ & $\mathrm{C}$ & $\mathrm{CD}$ & D & DE & E \\
\hline
\end{tabular}

Table 7 Site magnification coefficients (Atkinson and Boore 2003)

\begin{tabular}{lllllll}
\hline $\begin{array}{l}\text { Site } \begin{array}{l}\text { magnification } \\
\text { coefficients }\end{array} \\
F_{\text {PGA }}\end{array}$ & $\begin{array}{l}\text { Site } \\
\text { classifications }\end{array}$ & \multicolumn{5}{c}{ Bedrock ground motion peak (g) } \\
\cline { 3 - 7 } & & $\leq 0.1$ & 0.2 & 0.3 & 0.4 & $\geq 0.5$ \\
& $\mathrm{~B}$ & 1.00 & 1.00 & 1.00 & 1.00 & 1.00 \\
& $\mathrm{C}$ & 1.26 & 1.26 & 1.26 & 1.26 & 1.26 \\
$F_{\mathrm{a}}$ & $\mathrm{D}$ & 1.85 & 1.84 & 1.85 & 1.85 & 1.85 \\
& $\mathrm{~B}$ & 1.00 & 1.00 & 1.00 & 1.00 & 1.00 \\
& $\mathrm{C}$ & 1.55 & 1.39 & 1.24 & 1.12 & 1.00 \\
$F_{\mathrm{v}}$ & $\mathrm{D}$ & 1.74 & 1.51 & 1.32 & 1.15 & 1.00 \\
& $\mathrm{~B}$ & 1.00 & 1.00 & 1.00 & 1.00 & 1.00 \\
& $\mathrm{C}$ & 1.39 & 1.28 & 1.18 & 1.09 & 1.00 \\
& $\mathrm{D}$ & 1.95 & 1.66 & 1.40 & 1.18 & 1.00 \\
\hline
\end{tabular}

Table 8 Peak acceleration correction table for different site ground motion (Li et al. 2001)

\begin{tabular}{lllllll}
\hline Site class & \multicolumn{6}{l}{$\begin{array}{l}\text { I-type site ground motion intensity(peak acceleration) } \\
\text { Amax }(\mathrm{g})\end{array}$} \\
\cline { 2 - 7 } & 0.05 & 0.1 & 0.15 & 0.2 & 0.3 & 0.4 \\
\hline I & 1.00 & 1.00 & 1.00 & 1.00 & 1.00 & 1.00 \\
II & 1.50 & 1.45 & 1.40 & 1.33 & 1.25 & 1.18 \\
III & 1.10 & 1.00 & 0.90 & 0.80 & 0.70 & 0.60 \\
\hline
\end{tabular}

6.2 The comparison for study results of this article and existing achievements

Features below can be discovered by comparing the study results here with external existing achievements:
(1) The rule of site impact factor: for the same site class, it tends to get smaller with bigger PGA input; it will gradually increase along with the change from site classes I-III during smaller PGA input, whereas the weak soil layer in coastal site classes I-III has a less obvious magnification effect to PGA than hardpan to PGA during bigger PGA input. Moreover, it has a more obvious impact to long and medium period than to short period in response spectrum. The study results of this article share the same trend with external achievements.

(2) There are also some differences found in comparison. In external study achievements, few impact factors present a minification effect, especially in weak sites class III. For example, using non-linear analysis method, Li et al. (2001) gained smaller peak accelerations from sites class III than those from sites class II. Sites class III present a cushioning effect with bigger PGA input, which may be related to the nonlinear feature of weak soil under a large earthquake.

\section{Conclusions}

1. The statistical analysis results of the Fujian coastal areas and mountains illustrated that the surface soil ground motion response amplification factors will decrease with the increase of ground motion input intensity. And, the magnification coefficient increases following site classes with the order from site classes $\mathrm{I}_{0}, \mathrm{I}_{1}$, II, to III on the condition of the same ground motion input, whereas the magnification coefficient unexpectedly decreases when the ground motion peak of coastal III-type is over $0.15 \mathrm{~g}$. 
2. The site peak acceleration amplification factors gained in this article all show a magnification effect in ground motion actions of various site classes. The amplification factors of site-class III are smaller than site-class II's, except for a bigger amplification factor under $0.05 \mathrm{~g}$ low intensity input. It is mainly concerned with the thicker high-compressive weak soils existed in Fujian coastal areas. The finding, that site-class III present a cushioning effect with bigger PGA input which may be related to the non-linear feature of weak soil under a large earthquake, also shows a similarity with Chinese study results.

3. The comparison between the study results of home and abroad ground motion site impact and the site impact factors gained from the calculations of this article show that the results here share certain similarities with existing achievements, so that the results can be used for ground motion site impact correction.

\section{References}

Allen TI, Wald DJ (2007) Topographic slope as a proxy for Seismic site-conditions $\left(\mathrm{V}_{\mathrm{S}}{ }^{30}\right)$ and amplification around the globe. U.S. Geological Survey Open-File Report 2007-1357, 69 p
Atkinson GM, Boore DM (2003) Empirical ground-motion relations for subduction zone earthquakes and their application to cascadia and other regions. Bull Seismol Soc Am 93(4): 1703-1729

Chen K, Yu YX, Gao MT (2010) Research on ShakeMap system in terms of the site effect. Earthq Res China 26(1):92-102 (in Chinese)

Ding XH (1999) The active faults and earthquakes in the southeast coastal area of Fujian. Fujian Science and Technology Press, Fuzhou (in Chinese)

GB18306-2001 (2001) Seismic ground motion parameter zonation map of China[S]. Standards Press of China, Beijing (in Chinese)

GB50011 (2010) The code for seismic design of buildings. China Architecture \& Building Press, Beijing (in Chinese)

Hu YX (1999) The technical course of probabilistic seismic hazard analysis. Earthquake Publishing, Beijing (in Chinese)

Li XJ, Peng Q, Liu WZ (2001) Consideration of site effects for determination of design earthquake ground motion parameters. World Inf Earthq Eng 17(4):34-41 (in Chinese)

Lu HS, Zhao FX (2007) Site coefficients suitable to China site category. Acta Seismol Sin 29(1):65-76 (in Chinese)

Wald DJ, Eeri M et al (1999) TriNet "ShakeMaps": rapid generation of peak ground motion and intensity maps for earthquakes in southern California. Earthq Spectra 15(3):537-559

Wald DJ, Worden BC, Quitoriano V et al (2006) ShakeMap manual: technical manual, user's guide, and software guide. U.S. Geological Survey, Washington, DC 